\title{
EVENT-BASED DESTINATION MARKETING: THE ROLE OF MEGA-EVENTS
}

\author{
YING WANG AND XIN JIN \\ Department of Tourism, Sport and Event Management, Griffith University, Gold Coast, \\ Queensland, Australia
}

\begin{abstract}
Mega-events play an invaluable role in the development of many destinations. These events contribute significantly to the host destinations' economy, enhance the awareness of the destinations, encourage cultural exchange, and promote the preservation of local culture. This study adopts a narrative review method to indicate research production in the field of the effect of event-based destination marketing. The review proposes an event-based destination marketing model to delineate how event, destination, and market characteristics, as well as the degree of collaboration between event committee and destination marketing organization (DMO), may affect the effectiveness of eventbased destination marketing strategies (produce, price, place and promotion).
\end{abstract}

\section{Key words: Mega-events; Review; Event-based destination marketing}

\section{Introduction}

Events range from small community events to regional, hallmark, and internationally oriented mega-events, and are across different themes: cultural, business, and sports. Hallmark events are rooted in the destination tradition and culture. Reoccurring hallmark events, usually attached to a specific destination (Getz, 2008), have an ongoing effect on, and are closely related to, destination marketing, although the effectiveness of using hallmark events in regenerating or modifying destination image is understudied. Unlike hallmark events, mega-events are typically internationally orientated and highly visible, attracting tremendous media coverage and global attendance (Jafari, 1988). Most mega-events rotate among destinations; therefore, the opportunities for destination marketing may be short-lived without proper planning and management.

Mega-events play an invaluable role in the development of many destinations. For instance, the Eurovision Song Contest (regarded as a megacultural event) was used by Azerbaijan as an official strategy of incorporating mega-events into their attempt to develop international tourism, reduce the image of the country's dependence on oil, and to achieve long-term development (Arnegger \& Herz, 2016). Dubai also uses World Expo 2020 to 
further consolidate its image as a regional Meetings, Incentives, Conferences, and Exhibitions (MICE) center and a tourism destination (Kotsi \& Michael, 2015). A large number of studies have identified the benefits and costs of mega-events. Positive economic benefits come in the form of income, employment, and tax revenues (Getz, 1994, 2008). Socially, events enhance the awareness of the host destinations, encourage cultural exchange, and promote the preservation of local culture (H. J. Kim, Gursoy, \& Lee, 2006). Environmental benefits include an enhanced environmental awareness, the desire for the conservation of natural resources, and strengthened focus on minimizing carbon footprint (Jago, Dwyer, Lipman, van Lill, \& Vorster, 2010; H. J. Kim et al., 2006). More specifically for tourism, events increase tourist receipts and provide opportunities of business leverage, destination branding, and induced tourism (Chalip \& Costa, 2005; Dwyer, Mellor, Mistilis, \& Mules 2000; Getz, 2008; S. S. Kim \& Morrison, 2005; Singh \& Hu, 2008).

Hosting an event is an exercise of cobranding (Chalip, Green, \& Hill, 2003; Washburn, Till, \& Priluck, 2000); hence, its relevance to tourism destination marketing is evident. A study that synthesizes literature on (mega) events studies, with a focus on such events' links to destination marketing and place making, is critical, as it provides insights that help optimize marketing strategies based on mega-events. This study adopted a narrative review method. Journals in the field of tourism, hospitality, sports, and events management have been systematically searched with key word search using combinations of the phrases of: "mega-event," "hallmark events," "events study," "destination marketing," "tourism marketing strategies," "destination branding," "event marketing," and "event impacts.” With a purpose to explore the role of mega-events as a destination maker and tourism generator for a host destination, this article:

- discusses the scope of mega-events; and

- delineates how event, destination, and market characteristics, as well as the degree of collaboration between event committee and destination marketing organization (DMO), may affect the effectiveness of event-based destination marketing strategies.

\section{Topical Areas}

\section{Mega-Events: Scale, Scope, and Perspectives}

The conventional approach to define mega-events is based on the scale of the event and the sheer number of visitors attracted (Jafari, 1988). Megaevents are 'large scale events, marketed by global publicity, attracting substantial international visitation and associated with large scale economic, social and environmental impacts" (Jago et al., 2010, p. 222). Existing literature on mega-events focuses largely on sports events. There are three main categories of mega-events, including sports, cultural, and business (Jago et al., 2010). By broadening the definition of mega-events beyond sports events, cultural hallmark events (e.g., Eurovision in Arnegger \& Herz, 2016,) may be subsumed into the mega category, thereby expanding the scope of mega-events and blurring the boundary between mega-events and large-scale hallmark events. The latter is defined by Hall (1989) as, "major fairs, expositions, cultural and sports events of international status which are held either on a regular or a one-off basis. A primary function of the hallmark event is to provide the host community with an opportunity to secure high prominence in the tourism market place” (p. 263). Global publicity of the event and substantial tourist visitation characterized mega-events in both definitions.

Some events may not have this global orientation to attract a substantial percentage of international visitation. For example, only $5.8 \%$ of the 70 million visits to the 2010 Shanghai World Expo were foreign nationals, including those who were already in China for working or studying purposes (Chen, 2012). Similarly, some other large-scale events have created phenomenal economic, social, and environmental impacts but lack an international focus on publicity and visitation. These mega-events are particularly evidenced in heavily populated emerging countries like China. It is thus debatable if these large-scale events should be excluded from the discussion of mega-events.

Both Jago et al. (2010) and Hall (1989) draw a link between mega-events and tourism development. The former highlights the significant impact of mega-events for the destination and its communities at large, whereas the latter emphasizes the direct association between hallmark events and tourism 
development. Some academics argue that, from the tourism perspective, mega-events should be defined on the basis of the degree to which they force tourism development in the host destination (Jafari, 1988). For example, if the demand resulting from the event exceeds the capacity of the existing tourism infrastructure at the destination, further substantial investment in infrastructure will occur. The event should be considered a mega-event owing to its ability to induce significant tourism development. Nevertheless, current discourse on mega-events remains determined primarily on the basis of event scale.

\section{Effect of Events on Destination Marketing by Event Type}

A key question in event studies is whether business, cultural, and sports mega-events impact differently on host destinations' marketing strategies and the effectiveness of these strategies. Mega political/ government events (e.g., G20 and APEC summit) are regarded as business events (Getz \& Page, 2016). In effect, all three types of mega-events have the potential to create iconic tourist attractions. For example, Beijing National Stadium (also known as the Bird's Nest Stadium) stands as a legacy of the 2008 Beijing Olympic Games. The Hong Kong Convention and Exhibition Centre was constructed for the 1997 handover of Hong Kong to Mainland China ceremony and continues to function as the main venue for large-scale business events. The Chinese Pavilion remains a popular tourist attraction post the 2010 Shanghai World Expo. However, the three types of events differ in several aspects: economic, social-cultural, and environmental impacts; media coverage; the degree to which DMOs incorporate the event in their destination marketing strategies; as a primary motive to visit a destination; and effectiveness as a destination marker.

Sports mega-events create long-lasting infrastructure and leave a long-term legacy at the destination. There seems to be mounting evidence that mega-sports events have significant economic implications; for instance, Horne and Manzenreiter (2004) on the 2002 Football World Cup in Korea and Japan; Jones (2001) on the 1999 Rugby World Cup in Wales; Madden (2002) on the Sydney Olympic Games in 2000. Yet, within sports events, disparities occur in terms of the power of these events in stimulating tourism demand. The Summer Olympics and FIFA World Cup generated the most tourist arrivals, but the Cricket World Cup, the Winter Olympics, and the Rugby World Cup seemed incapable of making significant contributions (Fourie \& Santana-Gallego, 2011). Further, tourists from participating countries increase more than tourists from countries not participating in the mega-event (Fourie \& Santana-Gallego, 2011). Weed (2009) argued that the findings of economic impact analyses should not be taken at face value, and sometimes the results from different studies are not comparable due to two reasons: methodological incompetence and deliberate complication as a consequence of political pressure. Although there is a general consensus about the macroeconomic impacts of hosting mega-sports events, the exact nature and extent of these impacts remain unclear (Weed, 2009). In addition, critics have pointed out an overly dominant economic focus at the cost of social and environmental issues.

There is also a suggestion that studies on economic outcomes of sports events need to go beyond impact to leverage, which has a strategic and technical focus and is a more proactive approach to capitalize on opportunities sports events can provide (Weed, 2009). One way of leveraging is to incorporate these events in developing destination marketing mix. Sports mega-events have tremendous media coverage that may contribute to the formation of the destination image held by the global audience, as suggested by Brown et al.'s (2002) analysis of the 2000 Sydney Olympic Games' impact on "Brand Australia," Li and Kaplanidou's (2013) study of the impacts of the 2008 Beijing Olympic Games on China's destination brand, and most recently Knott, Fyall, and Jones' (2016) study on South Africa's leverage on 2010 FIFA World Cup for national image building. These games can create highly penetrable iconic pictures (e.g., the Bird's Nest and the Water Cube in Beijing) that have the capacity to improve or dispel outdated images of the destination (Lai, 2017).

Studies of this kind can inform effective marketing, which may have both positive and negative implications in each of the three realms, on triple bottom line sustainability for visitors and residents (Weed, 2009), arguing for the adoption of a leverage approach that not only maximizes benefits but also 
mitigates negative impacts. Hede (2005) found that the telecast of the 2004 Athens Olympics offered a vicarious experience of the destination, which helped develop a positive attitude among potential travelers to Greece as a tourist destination. Leveraging the media and social media is vital in mobilizing the local citizens to avoid potential damage to the destination brand: consider, for example, the social protests surrounding the 2014 FIFA World Cup held in Brazil (Knott et al., 2016). Stakeholders must be encouraged to "plan this process more deliberately to leverage the opportunity more effectively, before, during and most importantly, after the event” (Knott et al., 2016, p. 116). This highlights the importance of integrating destination and event marketing activities in the early stages of event planning to optimize tourism benefits from staging events in host destinations.

There is a growing recognition that business events make significant contributions to tourism at a destination. This nexus between tourism and business events has been discussed by a few scholars (e.g., Getz, 2008, Jago \& Deery, 2010), and benefits identified include increased visitation, higher yield market, and participation in pre- and posttours by business travelers and their companions. Business mega-events create infrastructure and capitalize on business-related opportunities. These events generate trade and commerce, and foster innovation. Therefore, the benefits go beyond what sports and cultural events can generate (Jago et al., 2010). However, there is a lack of research in identifying opportunities and approaches to leverage the benefits of business events beyond the obvious economic impact to the host destination.

Business events (with the exception of megapolitical events) have specific target audiences who travel primarily for the event. Despite their scale and international profile (e.g., CeBIT, a large international tech expo), the media coverage of these events tends to be within the relevant business sector. Their role in shaping the image of the destination among leisure tourists may be limited. A search of the literature yielded little empirical evidence on destinations using business mega-events in destination marketing. Even if these events are included in tourism-related marketing and promotional materials, the effectiveness of their ability to generate tourism demand is unknown. For example, having a history of close to six decades and attracting approximately 200,000 visitors (buyers) per session per year from more than 200 countries, the China Import and Export Fair (Canton Fair) as well as the host city (Guangzhou/Canton) are little-known to international tourists (Jin, 2006).

Cultural mega-events enrich local culture and way of life, which consequently contributes to the sense of the place and enhances its appeal to potential visitors. Therefore, they are important elements of destination marketing strategies. Most of these events not only showcase the host culture but also bring together cultures from around the world. The success of the Edinburgh International Festival in attracting international visitors relies significantly on its demonstration of international cultures (Prentice \& Andersen, 2003). The European Capital of Culture events acted as a catalyst for hosting cities, triggering the branding exercise of these cities (Nobili, 2005), and potentially contributing to cultural policy, heritage, and local identity (Cohen, 2013). Nevertheless, there is a lack of effectiveness of such cultural events in modifying destination image. As evidenced by Prentice and Andersen (2003), the Edinburgh International Festival was not able to alter the image of Scotland as a historical and rural destination.

Cultural mega-events may act as primary travel motivation for domestic visitors, but their effectiveness in generating international tourism demand is questionable. For example, the World Expo, as a cultural mega-event, seems to have attracted less attention in recent years. As mentioned above, in the case of the 2010 Shanghai World Expo, visitations were generated primarily from the domestic and regional markets (Chen, 2012). Further, within these markets, the event image did not affect tourists' overall attitude toward the destination; rather, its effect was completely mediated through its influence on destination image (Deng \& Li, 2013). Similarly, the 2012 Yeosu World Expo generated limited publicity resulting in low awareness of the event among potential travelers in culturally and geographically distant countries such as Australia.

\section{Effect of Events on Destination \\ Marketing by Destination Type}

The impact of mega-events differs across destination types (e.g., tourist vs. nontourist destinations; 
high profile vs. low profile destinations; urban vs. rural destinations). Event locations are predominantly selected by the hosting organizations. The choice of the hosting destination for a mega-sports event (e.g., the Olympic Games) is determined on the bases of the destination's ability to supply game-specific infrastructure and the political will at the destination for hosting the event, usually through a bidding process (Persson, 2002). Host cities are typically highly populated metropoles with well-developed economies and a strong institutional capacity (Singh \& Zhou, 2016). Most megabusiness events are fixed to an urban metropolis with an infrastructure and business environment suitable for the particular event theme. Some cultural events (e.g., folk or music festivals) are hosted in rural destinations. The diversity in destination characteristics alludes to a varied effect of events on destination marketing.

For destinations to capitalize on mega-events, there must be a financing environment friendly for tourism investment in order to build tourism bubbles for international visitation (Andranovich, Burbank, \& Heying, 2001). One would assume that such a demand is less of an issue in well-known tourism destinations where there is an abundant supply of tourism infrastructure. Popular tourist destinations may require less effort in international marketing. This is because these cities with their high profiles tend to enjoy a high level of organic images that would need to be created for destinations little known to international visitors. Further, for destinations still in the developing phase, or destinations with an increasing level of urban poverty, investments on mega-events and tourism have to compete with projects aiming to improve economic and social conditions for residents (Andranovich et al., 2001), creating challenges to obtain funding for tourism-related activities.

In theory, mega-events generate direct and indirect revenues that should benefit residents at large (Lambert, Noci, Guo, \& Zhu, 2011). However, in reality, mega-events fail to lead to poverty alleviation and urban revitalization in many cases. In the cases of the 1984 Los Angles Olympic Games, the 1996 Atlanta Olympic Games, and the 2002 Salt Lake City Winter Olympic Games, all three cities witnessed development of essential tourism infrastructure and leisure facilities, yet these events did not result in successful urban regeneration (Andranovich et al., 2001).

The selection of Winter Olympic host cities is restricted by the requirement of infrastructure for snow- and ice-based sports. Thus, all the host cities are located in the high latitude region in the Northern hemisphere. The majority of the host cities are not major metropoles. Based on a 5-year longitudinal study focusing on the impact of 1988 Calgary Olympic Winter Games, Ritchie and Smith (1991) found that the event dramatically increased the awareness of the city in the European and North American markets and substantially modified the image of the city. Nevertheless, this impact decreases considerably after a short period of time. The Games' ability to attract the culturally and/or geographically distant tourism market after the event is questionable. Likewise, S. S. Kim and Morrison's (2005) study has shown that as a result of the 2002 FIFA World Cup, the image of South Korea changed positively among the Mainland Chinese group, while it remained similar among the American group. The special natural environment and/or geographic conditions (e.g., mountains, seas, lakes, and forests) offer these destinations an opportunity to expand into the markets of niche tourism and events, improving destination image and increasing revisitation (Hallmann, Zehrer, \& Müller, 2015).

\section{Effect of Events on Destination Marketing by Customer Type}

There are various types of customers of events: spectators, viewers, and participants at sports events; attendees and delegates of conferences; exhibitors and visitors to expositions; performers and participants to cultural events. Customer groups differ in motivation, expectation, channel of communication, information need, and mode of travel (e.g., Arnegger \& Herz, 2016; Carlson, Rosenberger III, \& Rahman, 2015). Their interactions with the destination and their touristic needs vary based on the event type. It is reasonable to assume that subgroups of spectators/attendees would respond to event and destination marketing differently. Many mega-events are recurring events, implying that the market may be subject to multiple exposures to promotional information across years. Some customers may have prior experiences attending the event 
or may have visited the host destination. They may or may not be satisfied with their visits. In the context of competitive sports events, the performance of the team they support can directly influence their event experience, yet there is a paucity of literature that has explicitly tested these issues. Research on sports events suggests that customers can be segmented based on their desire to learn about the destination (N. S. Kim \& Chalip, 2004), interest in visiting the destination (Li \& Kaplanidou, 2013), and familiarity with a host destination (Chalip et al., 2003), as well as sociodemographics such as gender, age, and education (O’Reilly et al., 2016).

N. S. Kim and Chalip (2004) found the likelihood that Americans would attend the World Cup in Korea increased if they could also obtain opportunities to learn about Korea. Li and Kaplanidou (2013) studied the collective perception of China by US travelers before and after the 2008 Beijing Olympic Games. Various subgroups of this market showed different levels of likelihood in perception change during this process. Those interested in visiting the Greater China Area and those who are not interested in visiting Asia at all showed positive improvement in their perceptions of China's destination brand. Interestingly, those interested in visiting Asian countries other than China displayed a negative perception change. This finding is in line with Dolničar's (2004) proposition that interest in destination is a useful segmentation criterion for destination marketing. Olympic media coverage following the event led to a more positive attitude toward China, and the more exposure people had to Olympic media the more favorable view they held about China. Additionally, Arnegger and Herz (2016) posited that, regardless of the event experience, the overall media coverage around Eurovision is sufficient to enhance people's knowledge and intention to visit.

The effect of media on destination image can vary as a result of the market's familiarity with a host destination (Chalip et al., 2003). In markets where there is very little tourism advertising of the destination, the effect of media tends to have a more substantial positive effect. This is because the information communicated to the market is new and fresh, resulting in a higher likelihood of influencing perception. From a strategic perspective, DMOs at the host destinations should identify and target specific market segments based on their relevant segmentation criteria.

\section{Effect of Events on Destination Marketing by DMO-Event Collaboration}

Events often exist temporarily at a destination, but tourism is not temporary in nature, and demand for tourism exists before, during, and after the event (Singh \& Hu, 2008). Organizations that hold ownership of mega-events are not stakeholders who benefit from long-term impacts of these events on the destination. Consequently, they are not interested in being part of the strategies generating long-lasting prosperity of the destinations (Jago et al., 2010).

In the early days of mega-events there was little to no indication that host cities formally incorporated events into their tourism strategies. A case study of the 1991 World Student Games in Sheffield suggested that the host city was very slow to develop a formal master plan. The year before the event a director of tourism was appointed to link the Games investment with tourism, and the event was identified as one of the five tourism strengths of the city to be further developed and promoted. However, it was only 3 years after the Games that a formal strategy was developed for general and tourism promotion of the city, which focused on its year-round events program (Bramwell, 1997). Later events have recognized the opportunity for cross-leverage of events with their host destinations; however, evidence from Australia (Chalip \& Leyns, 2002), the UK (Weed, 2009), and the US (Ahmed, Krohn, \& Heller, 1996) shows a lack of effectiveness in cross-leverage. These findings are surprising given the substantial gain from a robust marketing alliance for both event marketers and DMOs (Chalip \& McGuirty, 2004).

The 2008 Olympic Games forced the Beijing tourism department, government organizations, and industry stakeholders to work collaboratively to shift Beijing's image from an historically significant destination to a new image of an economically strong and technologically advanced nation. However, as time has passed since the games, the tourism department has reverted to its former conventional promotional strategies (Singh \& Zhou, 2016). 
Event media can complement tourism advertising but, in some cases, it can also undermine tourism advertising. In the case of Gold Coast IndyCar race, a lack of event media exposure of the natural environment of the Gold Coast resulted in a depressive effect on the market's perception of the city's natural attractions. This highlights the importance of collaborative marketing between event media and DMO promotion.

The nature of an event could limit the extent to which tourism attributes can be incorporated in event marketing (Chalip et al., 2003). In relation to the 2004 Athens Olympic Games, Singh and Hu's (2008) study on the strategic alignment between destination marketing and the Games revealed a lack of communication and collaboration between the two organizations. The DMO made effort in using the event to improve its tourism facilities and to enhance the image of Athens. It also had to run special campaigns to address game-induced negative publicity, such as delays in planning Game activities, increase in terrorism, and inflated accommodation cost. The study suggested that proper and timely coordination between the two organizations could have increased event revenue as well as avoided negative publicity. Successful event-based marketing requires strategies and operations that involve two knowledge domains, namely Olympic planning and destination marketing (Singh \& $\mathrm{Hu}$, 2008); however, it is the DMO's primary responsibility to develop, coordinate, and align their tourism strategies carefully with the event. Ahmed et al. (1996) suggested that the World University Games in Buffalo, New York did not generate a satisfying economic impact because local businesses failed to cultivate spending by event visitors. DMOs thus need to engage in internal marketing to communicate to local businesses the event's benefits and means of profiting from events.

The involvement of multiple stakeholders complicates the planning and delivery of an event and its associated marketing outcomes. This is evidenced in the case of 2014 Pan Pacific Swimming Titles hosted on the Gold Coast, used as a test event of the 2018 Commonwealth Games. The main swimming venue features a debatable design without a roof. The concern is that this may detract from the city's goal to showcase its tourism assets, and it demonstrates an insufficient consideration (and possibly lack of consultation) of the needs of sports and events stakeholders (e.g., organizations and users of facilities), resulting in a massive disaster for both the event and tourism stakeholders. Competitions and spectators complained about the bad weather with rain and high winds during the events, and the pictures of a rain-soaked Gold Coast were broadcast worldwide. Stakeholder collaboration must start from the very early stages of event-related planning, such as venue design and urban regeneration plan. The collaboration must be maintained throughout and after the event. It is also vital that a crisis recovery strategy be put in place in the event of negative media coverage (Fairley, Lovegrove, Newland, \& Green, 2016).

Mega-events offer destinations opportunities to enhance their product, place, price, and promotionthe four P model (McCarthy, 1960). Although various versions of the event marketing mix (e.g., Allen, O’Toole, Harris, \& McDonnell, 2011) have been developed, their relevance to tourism is limited. To treat a mega-event as an integral element of the tourism offering, we developed an event-based destination marketing model (Fig. 1) building on the traditional four Ps. Our model outlines how the destination and the event can be integrated into each of the four Ps so that DMOs can manipulate them to achieve effective event-based marketing. Out of the four Ps, product and promotion have attracted much of the discussion in the extant literature, whereas little attention was given to how mega-events can influence place and price.

Events offer immerse opportunities for placing marketing in relation to product and promotion. As the review demonstrates, events can expand destination product portfolio and infrastructure system. These contribute to the building of a sense of place, which consequently enhances destination reputation and image. An expanded and enriched eventdestination product is a unique opportunity for the destination to differentiate itself from its competitors. The cobranding between tourism and events requires collaborative marketing for both to leverage on media coverage. In the event of undesirable publicity, the collaborative spirit should mediate the impact on individual stakeholders. The limited focus on place and price may be explained by the fact that DMOs have little control over these factors. Place and price present challenges to destinations. 


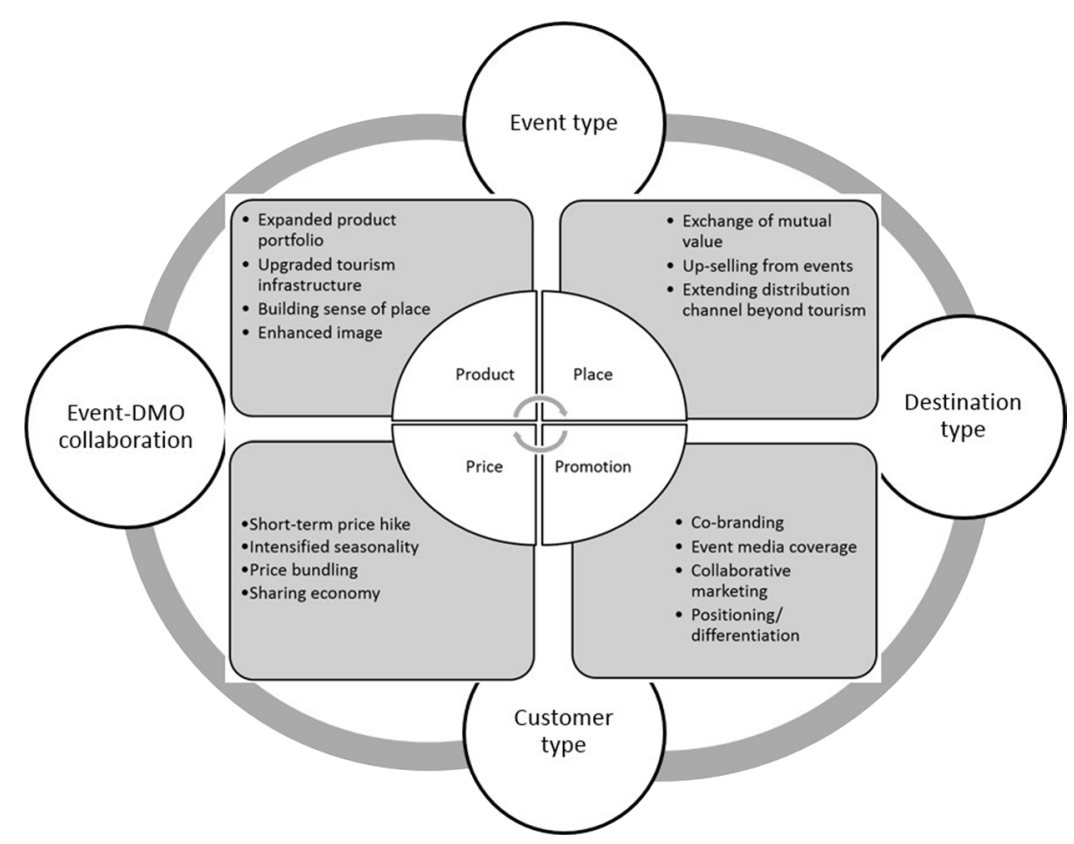

Figure 1. Event-based marketing: Four Ps.

Different from small or medium events that destinations typically target to fill capacities in low seasons, mega-events with a more fixed calendar often intensify seasonality and short-term price hikes. One concern of the destination is the limited consumption of local tourism products by mega-event attendees due to their focus on events. A strategy to encourage tourism consumption is through bundling event ticket sales with that of local tourism products (e.g., local attractions). Such efforts have the potential to redistribute event attendees, thereby reducing the pressure on the core event precinct. The concept of the sharing economy also offers the potential to reduce price hikes through accessing underutilized accommodation and transportation capacities already in existence at the destination. Effective place requires high levels of involvement with complementary distribution channels for the purpose of exchange of mutual values. An integrated/ coordinated distribution effort can provide upselling opportunities from the events for tourism providers and extend their distribution channels beyond tourism. Responding to the challenges with regards to place and price, DMOs need to shift their thinking from marketing towards management to facilitate long-term planning and collaboration across stakeholders. Factors identified in our review, namely event type, destination type, customer type, and event-DMO collaboration, moderate the interactions between the destination and event.

\section{Conclusion}

This article discusses a number of aspects related to destination leveraging on mega-events, including the scale and scope of events, and their impacts on destination marketing from four perspectives: event type, destination type, customer type, and DMOevent collaboration. The review suggests that effective marketing requires a holistic and systematic approach that considers the aforementioned factors. We conclude that in order to optimize the benefits from events, DMOs need to employ both external and internal marketing strategies. The latter, especially, has not attracted academic attention.

Successful event-based destination marketing faces a number of challenges. One such challenge is insufficient empirical evidence to inform effective marketing planning and design. The event-based marketing model provides a framework to extend research in this regard. Another challenge is the difficulty of collaboration resulting from the different 
(and sometimes conflicting) interests of the event committee and the DMO. The four Ps must be operationalized in this particular context. In addition, there are also conflicting interests between the public and private sectors (e.g., the event organizing committee and corporate sponsors). Studies offering suggestions and solutions to these challenges will contribute to the understanding of how megaevents enrich tourism destination development and marketing. To benefit from mega-events, destinations must consider a number of key success factors including cultural content, place context, the power dynamics, stakeholder relationships, resources, and long-term planning (Richards \& Palmer, 2012). Resource and knowledge-based theories offer solid theoretical underpinnings for formulating strategies for event destinations to achieve effective stakeholder alliance and competitive advantage. To enable the 4Ps illustrated above, destinations must analyze their internal resources and strategically use these as a source of direction to optimize their capacity to achieve event-induced tourism goals. In particular, strategy formulation from a knowledgebased view (e.g., knowledge sharing and transfer) could be useful to address the lack of collaboration arising from different stakeholder agendas.

\section{Acknowledgment}

The authors contributed equally to the research.

\section{References}

Ahmed, Z. U., Krohn, F. B., \& Heller, V. L. (1996). World University Games-1993 at Buffalo (New York): Boosting its tourism industry or missing an opportunity-An international marketing perspective. Journal of Professional Services Marketing, 14(2), 79-97.

Allen, J., O’Toole, W., Harris, R., \& McDonnell, I. (2011). Festival and special event management (5th ed.). Milton, Australia: John Wiley \& Sons Australia.

Andranovich, G., Burbank, M. J., \& Heying, C. H. (2001). Olympic cities: Lessons learned from mega-event politics. Journal of Urban Affairs, 23(2), 113-131.

Arnegger, J., \& Herz, M. (2016). Economic and destination image impacts of mega-events in emerging tourist destinations. Journal of Destination Marketing \& Management, 5(2), 76-85.

Bramwell, B. (1997). Strategic planning before and after a mega-event. Tourism Management, 18(3), 167-176.

Brown, G., Chalip, L., Jago, L., Mules, T., Morgan, N., Pritchard, A., \& Pride, R. (2002). The Sydney Olympics and brand Australia (pp. 163-185). Oxford, UK: ButterworthHeinemann Ltd.

Carlson, J., Rosenberger III, P. J., \& Rahman, M. M. (2015). Cultivating group-oriented travel behaviour to major events: Assessing the importance of customer-perceived value, enduring event involvement and attitude towards the host destination. Journal of Marketing Management, 31(9-10), 1065-1089.

Chalip, L., \& Costa, C. A. (2005). Sport event tourism and the destination brand: Towards a general theory. Sport in Society, 8(2), 218-237.

Chalip, L., Green, B. C., \& Hill, B. (2003). Effects of sport event media on destination image and intention to visit. Journal of Sport Management, 17(3), 214-234.

Chalip, L., \& Leyns, A. (2002). Local business leveraging of a sport event: Managing an event for economic benefit. Journal of Sport Management, 16, 132-158.

Chalip, L., \& McGuirty, J. (2004). Bundling sport events with the host destination. Journal of Sport \& Tourism, 9(3), 267-282.

Chen, N. (2012). Branding national images: The 2008 Beijing Summer Olympics, 2010 Shanghai World Expo, and 2010 Guangzhou Asian Games. Public Relations Review, 38(5), 731-745.

Cohen, S. (2013). Musical memory, heritage and local identity: Remembering the popular music past in a European Capital of Culture. International Journal of Cultural Policy, 19(5), 576-594.

Deng, Q., \& Li, M. (2013). A model of event-destination image transfer. Journal of Travel Research, 53(1), 69-82.

Dolničar, S. (2004). Beyond “commonsense segmentation”: A systematics of segmentation approaches in tourism. Journal of Travel Research, 42(3), 244-250.

Dwyer, L., Mellor, R., Mistilis, N., \& Mules, T. (2000). A framework for assessing "tangible" and "intangible" impacts of events and conventions. Event Management, 6(3), 175-189.

Fairley, S., Lovegrove, H., Newland, B. L., \& Green, B. C. (2016). Image recovery from negative media coverage of a sport event: Destination, venue, and event considerations. Sport Management Review, 19(3), 352-360.

Fourie, J., \& Santana-Gallego, M. (2011). The impact of mega-sport events on tourist arrivals. Tourism Management, 32(6), 1364-1370.

Getz, D. (1994). Event tourism: Evaluating the impacts. In J. R. Brent Ritchie \& C. R. Goeldner (Eds.), Travel, tourism, and hospitality research: A handbook for managers and researchers (pp. 437-450). New York, NY: Wiley.

Getz, D. (2008). Event tourism: Definition, evolution, and research. Tourism Management, 29(3), 403-428.

Getz, D., \& Page, S. J. (2016). Progress and prospects for event tourism research. Tourism Management, 52, 593-631.

Hall, C. M. (1989). The definition and analysis of hallmark tourist events. GeoJournal, 19(3), 263-268.

Hallmann, K., Zehrer, A., \& Müller, S. (2015). Perceived destination image: An image model for a winter sports 
destination and its effect on intention to revisit. Journal of Travel Research, 54(1), 94-106.

Hede, A. M. (2005). Sports-events, tourism and destination marketing strategies: An Australian case study of Athens 2004 and its media telecast. Journal of Sport Tourism, 10(03), 187-200.

Horne, J. D., \& Manzenreiter, W. (2004). Accounting for mega-events forecast and actual impacts of the 2002 Football World Cup Finals on the host countries Japan/ Korea. International Review for the Sociology of Sport, 39(2), 187-203.

Jafari, J. (1988). Tourism mega-events. Annals of Tourism Research, 15(2), 272-273.

Jago, L., \& Deery, M. (2010). Delivering innovation, knowledge and performance: The role of business events. Spit Junction, Australia: Business Events Council of Australia.

Jago, L., Dwyer, L., Lipman, G., van Lill, D., \& Vorster, S. (2010). Optimising the potential of mega-events: An overview. International Journal of Event and Festival Management, 1(3), 220-237.

Jin, X. (2006). Guangzhou and its prospect as an international exhibition centre: The perceptions of the UK exhibitors and those of the Asian exhibition organizers. Proceedings of Third China Tourism Forum, Hong Kong SAR.

Jones, C. (2001). Mega-events and host-region impacts: Determining the true worth of the 1999 Rugby World Cup. International Journal of Tourism Research, 3(3), 241-251.

Kim, H. J., Gursoy, D., \& Lee, S. B. (2006). The impact of the 2002 World Cup on South Korea: Comparisons of pre-and post-games. Tourism Management, 27(1), 86-96.

Kim, N. S., \& Chalip, L. (2004). Why travel to the FIFA World Cup? Effects of motives, background, interest, and constraints. Tourism Management, 25(6), 695-707.

Kim, S. S., \& Morrison, A. M. (2005). Change of images of South Korea among foreign tourists after the 2002 FIFA World Cup. Tourism Management, 26(2), 233-247.

Knott, B., Fyall, A., \& Jones, I. (2016). Leveraging nation branding opportunities through sport mega-events. International Journal of Culture, Tourism and Hospitality Research, 10(1), 105-118.

Kotsi, F., \& Michael, I. (2015). Planning and developing 'Destination Dubai' in the context of the United Arab Emirates (UAE). In N. D. Morpeth \& H. Yan (Eds.), Planning for tourism: Towards a sustainable future (pp. 149-168). Wallingford, UK: CABI.
Lai, K. (2017). Influence of event image on destination image: The case of the 2008 Beijing Olympic Games. Journal of Destination Marketing \& Management, 17, 153-163.

Lambert, L., Noci, G., Guo, J., \& Zhu, S. (2011). Megaevents as drivers of community participation in developing countries: The case of Shanghai World Expo. Tourism Management, 32(6), 1474-1483.

Li, X. R., \& Kaplanidou, K. K. (2013). The impact of the 2008 Beijing Olympic Games on China's destination brand: A US-based examination. Journal of Hospitality \& Tourism Research, 37(2), 237-261.

Madden, J. R. (2002). The economic consequences of the Sydney Olympics: The CREA/Arthur Andersen study. Current Issues in Tourism, 5(1), 7-21.

McCarthy, E. J. (1960). Basic marketing: A managerial approach. Homewood, IL: Richard D. Irwin, Inc.

Nobili, V. (2005). The role of European capital of culture events within Genoa's and Liverpool's branding and positioning efforts. Place Branding, 1(3), 316-328.

O’Reilly, N., Armenakyan, A., Lu, I. R., Nadeau, J., Heslop, L. A., \& Cakmak, E. (2016). Sport mega-events and tourism: Contrasting the influence of host country and event. International Journal of Sport Management and Marketing, 16(3-6), 280-296.

Persson, C. (2002). The Olympic Games site decision. Tourism Management, 23(1), 27-36.

Prentice, R., \& Andersen, V. (2003). Festival as creative destination. Annals of Tourism Research, 30(1), 7-30.

Richards, G., \& Palmer, R. (2012). Eventful cities. Oxford, UK: Butterworth-Heinemann Ltd.

Ritchie, J. B., \& Smith, B. H. (1991). The impact of a megaevent on host region awareness: A longitudinal study. Journal of Travel Research, 30(1), 3-10.

Singh, N., \& Hu, C. (2008). Understanding strategic alignment for destination marketing and the 2004 Athens Olympic Games: Implications from extracted tacit knowledge. Tourism Management, 29(5), 929-939.

Singh, N., \& Zhou, H. (2016). Transformation of tourism in Beijing after the 2008 Summer Olympics: An analysis of the impacts in 2014. International Journal of Tourism Research, 18(4), 277-285.

Washburn, J. H., Till, B. D., \& Priluck, R. (2000). Cobranding: Brand equity and trial effects. Journal of Consumer Marketing, 17(7), 591-604.

Weed, M. (2009). Progress in sports tourism research? A meta-review and exploration of futures. Tourism Management, 30(5), 615-628. 